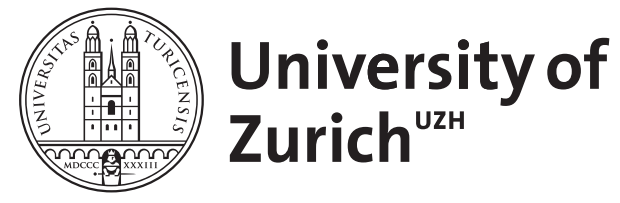

\title{
Martin Lindauer
}

Wehner, Rüdiger

DOI: https://doi.org/10.1007/s00359-009-0413-z

Posted at the Zurich Open Repository and Archive, University of Zurich ZORA URL: https://doi.org/10.5167/uzh-156014

Journal Article

Published Version

Originally published at:

Wehner, Rüdiger (2009). Martin Lindauer. Journal of Comparative Physiology A, 195(2):217-220.

DOI: https://doi.org/10.1007/s00359-009-0413-z 


\title{
Martin Lindauer
}

\author{
Rüdiger Wehner
}

Published online: 23 January 2009

(C) Springer-Verlag 2009

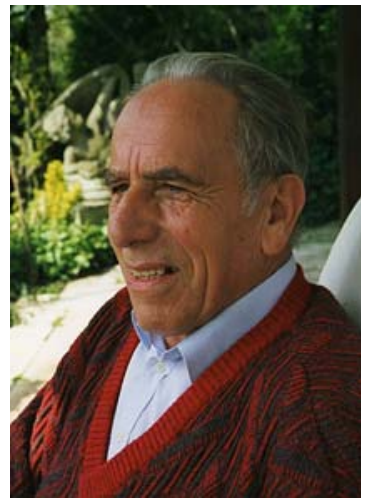

Martin Lindauer, in 1994

On 13 November 2008, 5 weeks before he was to celebrate his 90th birthday, Martin Lindauer-one of the greatest and most influential behavioural biologists and sensory physiologists of the twentieth century-passed away. During his last years of life he increasingly suffered from Parkinson's disease, but due to the devoted and loving help and encouragement of his wife Rosemarie he remained in contact with colleagues and former students, and kept up a keen interest in their ongoing research projects. I vividly recall how only a few years ago he and Rosemarie visited us in Zurich. Even though he was already heavily marked with his disease, upon arrival he immediately asked me to arrange a Saturday-morning seminar in which my graduate students would deliver 15-min talks about their most recent results. In the discussions following each talk Martin Lindauer was,

R. Wehner ( $\square)$

Institute of Zoology and Brain Research Institute,

University of Zürich, Winterthurerstr. 190,

8057 Zurich, Switzerland

e-mail: rwehner@zool.uzh.ch

as we-his former students—already knew well from our earlier days, inquisitive, full of sagacity and wit, instantly grasping the essential, and above all charmingly encouraging to the students.

Born on 19 December 1918 as the 11th of 15 children of Matthias and Katharina Lindauer, Martin grew up in a farmer's family. His father owned and farmed about 100 acres of poor pastureland. The farm in the hamlet Wäldle was located near the town of Bad Kohlgrub in southern Bavaria. Martin attended the local public school and excelled so well that Monsignore Lang, a priest from the near-by monastery in Landshut, provided him with a scholarship to the famous private high school in Landshut, then a Catholic boarding school connected to the Landshut monastery, and now the Hans Carossa Gymnasium. In this traditional humanistic high school Martin Lindauer received intensive education in ancient languages and the arts, but only little training in the sciences. In the final examination, the so-called Matura, he even had to write his major essay in Latin. The title was "Mens agitat molem" (freely translated: the mind drives the material world), and Lindauer began by describing how he and the entire family had to clear the stones from the meadows of their farmland, so that finally potatoes could be grown in the poor soil.

After Lindauer had successfully received his Matura degree in 1939, 6 months before World War II broke out, he had to join the Work Service and finally the army. These were difficult times for him at least in so far as he had never become a member of the Hitler Youth organization and hence was considered by his comrades as politically incorrect. In 1942 the anti-tank unit in which he served as a motorcycle messenger was transferred from the western to the eastern front, from France to the "Stalin Line" in Russia. There, next to the town of Tereschpol, an exploding grenade severely wounded his left arm. Lindauer was sent 
to a hospital in Munich and finally discharged from the army. This injury, which caused his left arm to remain partly paralyzed, had the fortunate effect of preventing Lindauer from joining the march to Stalingrad, where nearly all the men of his company died.

Immediately after his release from the army, Lindauer started his biology studies at the University of Munich. There Karl von Frisch must have been so impressed by the talented young man who had just returned wounded from the battlefield that shortly before Germany surrendered in May 1945, he invited Lindauer to join him as a Ph.D. student. In the interim, however, Karl von Frisch had retreated to his family resort "Brunnwinkl" at the Lake Wolfgang in Austria and was to accept the offer to become Professor of Zoology at the University of Graz. This meant that Martin Lindauer was left completely on his own while working on his thesis project in Munich. It might have been partly due to this independence from his thesis adviser that his keen powers of observation and his intuitive way of finding golden mines in research allowed him to transcend the somewhat conventional (not to say boring) thesis topic that von Frisch had given him (the influence of food scent and food taste on the bees' recruitment dances). By discovering how individual bees assessed both the profitability of a food source and the nutritional need of the colony, and how they adjusted their dances accordingly, Lindauer paved the way for the foundation of a new field of research that could be dubbed "sociophysiology", the study of the inner workings of a superorganism, in his case, the honey bee colony.

Having finished his Ph.D. thesis in 1947 Lindauer became Karl von Frisch's closest co-worker as a scientific assistant first in Graz (1948-1950) and then in Munich, until von Frisch retired in 1958. During these 10 years he did the work for which he has become world-renowned. In studying honey bee behaviour at the individual and the group level, in particular, by enquiring about how bees handled and used information obtained outside the hive and how they communicated this information among the members of their superorganismic unit inside the hive, he excelled in two domains: behavioural physiology and behavioural ecology. In doing so he dealt with both the proximate and the ultimate causes of behaviour, long before these technical terms had been coined and the proper concepts had been developed. Let me illustrate Lindauer's lucid conceptual and painstaking experimental approaches by referring to three of his major research projects: the first about the orientation behaviour of individual bees (how foragers acquire the local solar ephemeris function of their celestial compass), the second about the economy of the hive (how bees monitor and meet the continually changing energy demands of their colony), and the final one about the evolutionary history of the dance language.
In the first example, Lindauer showed convincingly that bees do not come genetically programmed with a fixed knowledge about the daily course of the sun that is valid for the particular time of year and the particular geographical latitude at which they happen to live. Based on faulty experiments, the latter erroneous possibility had been proposed by other workers in the field. But Lindauer's experiments made it clear beyond any doubt that the bees had to acquire at least the details of the sun's daily ephemeris function during the first days of their outdoor lives, and that inborn and individually acquired components of how this time-compensation occurred were intricately intertwined. $\mathrm{He}$ arrived at these conclusions by letting incubator-reared bees experience only a small portion of the sun's daily course and by later testing how they behaved at times at which they had never seen the sun before. Finally he substantiated his conclusions by transferring honey bee queens from the northern hemisphere, from California, to the southern hemisphere, to Brazil, where their northern (light coloured) progeny was raised in foster colonies of (darkcoloured and hence easily distinguishable) South American bees. Upon starting their foraging lives the northern bees immediately realized that in their southern environment the sun moved counter-clockwise across the sky rather than clockwise, as is the case in northern latitudes. To read Lindauer's papers on this subject is a delight. One enjoys not only the sophisticated experimental paradigms he carefully applied in these studies, but also his brilliant way of arguing that, if one considered the full scope of the underlying computational problem, the bees could not have behaved otherwise.

It is the same combination of crystal-clear theoretical reasoning and exacting experimental design that characterizes the second example that I would like to address in this biographical memoir, and for which Lindauer has certainly become most famous. Here his gaze shifted from the perspective of the organism to that of the colony, whose survival he considered to be the result of an "intelligent" exchange of goods by the individuals. Using the bees' recruitment dances as an experimental tool Lindauer was able to show that the foraging success of the colony depended on the fine-tuning of the foragers' nectar intake rate to the colony's varying energetic needs. He unravelled in unprecedented quantitative detail how the individual bees adopted particular behavioural stratagems in adjusting their dance thresholds and food delivery times inside the hive as well as their food quality assessments outside the hive in the most economic way-as if the entire chain of events were governed by the proverbial Invisible Hand. In pursuing these types of questions Lindauer must have intuitively anticipated that a new research perspective would arise: self-organization in biological systems; the notion that global high-level organization could result from 
interactions among local low-level components. Justifiably, Lindauer's pioneering "sociophysiological" studies, which included not only his work on foraging economy mentioned above, but also detailed studies on task adjustments of individuals (division of labour) and house hunting by split-off colonies, have become stepping stones for these new conceptual developments-for the emergence of the concepts of self-organization and superorganismic biological structures.

In the third research project, which also was to become a classic, Lindauer inquired about the phylogenetic origin of the bees' recruitment dances. He travelled to South America and Sri Lanka (then Ceylon) to study the stingless bees, the Meliponini, and the Asian relatives of the European honey bees, the Apini. In the latter he concluded that the open-nesting dwarf bee, Apis florea, was closest to the ancestral bee from which the dance language evolved, because it already oriented its dances, which it performed on top of its single exposed comb, to celestial cues, but lacked the ability to translate the sun-defined courses of its dances into gravity-defined ones. In addition, he inferred that the dwarf bees diverged early from the ancestral Apis clade, and that the open-nesting rock bees, e.g. Apis dors$a t a$, split off later from the lineage that finally led to the hive bees, e.g. Apis cerana and Apis mellifera. Notwithstanding some details that later completed the picture, these inferences have recently been supported by studies in molecular systematics.

In 1963 Martin Lindauer became Professor of Zoology at the University of Frankfurt. By now the scientific tide had turned. With Hansjochem Autrum succeeding Karl von Frisch in Munich, and Dietrich Burkhardt, one of Autrum's students, joining Lindauer in Frankfurt, intracellular electrophysiological recordings had become the dominant approach in neurobiology. Concomitantly, Lindauer's interests shifted towards sensory physiology. Visual, olfactory and even magnetoreceptive performances of honey bees became major research topics. However, in university affairs the tide had turned as well. A few years after Lindauer had arrived at Frankfurt he found himself embroiled in what has become known as the student revolt. Fully devoted to time-consuming research and continually encouraging his graduate students to do the same, he was particularly troubled by the anti-science touch of this political movement. Hence, in hindsight, he certainly must have regretted not having accepted a call in 1967 to become Professor at the newly founded University of Konstanz. Finally, however, after 10 creative years in Frankfurt, where in spite of the prevailing difficult conditions he had succeeded in establishing a strong research community in behavioural biology and sensory physiology, he moved to Würzburg and so returned to his beloved home-state Bavaria. At Würzburg University he became increasingly engaged in science policy and served as Dean and Vice President, remaining as ever idealistic about the university and its great mission in research and teaching. He retired in 1987.

From very early on Lindauer's achievements had been well recognized internationally. Already in 1959, when he was still a research assistant in Munich, he was invited to deliver the prestigious Prather Lectures in Biology at Harvard University. These lectures resulted in a book entitled "Communication among Social Bees", published by Harvard University Press. Soon thereafter he received calls to become Professor at the University of Ottawa (1960), the University of Syracuse (1961), and was even invited to consider a move to Harvard University (1961). But he declined all these offers. Among the many honours he received later in his career are the memberships of the National Academy of Sciences of the USA and the German Academy of Science (Leopoldina), the First Class Order of the Federal Republic of Germany, the Karl von Frisch Medal, the Bavarian Maximilian Medal as well as honorary doctorates from the Universities of Zurich (Switzerland), Saarbrücken (Germany) and Umea (Sweden).

More than anything else, Martin Lindauer inspired many of us as a person whose dedication to his scientific work, whose intellectual curiosity and absolute decency made him a role model. In supervising his doctoral students he credited them with complete freedom in developing their concepts, research plans, and experimental devices, but he had high standards and expectations for what he wanted them to achieve, and demanded their full commitment to their research projects. I shall never forget the day when he asked me to break off the relations I had kept up, since my early interests in ornithology, with the Senckenberg Research Institute and Natural History Museum in Frankfurt. While starting to establish a strong research group in experimental biology, Lindauer argued that for his students faunistics and systematics were distracting fields of interest, worn down and no longer at the cutting edge of contemporary science. But he again proved himself to be a visionary leader when soon thereafter functional morphology, phylogenetic systematics and evolutionary biodiversity studiesdisciplines covered mainly by museum-bound research groups-started to re-gain momentum and scientific respectability. Now he called me again and asked me whether I could re-establish my former connections with the Senckenberg Institute (connections which-as I then had to confess-I had actually never broken off) and help in fostering co-operations between "Senckenberg" and the University. Indeed, Lindauer had strong opinions about what he had to expect from his students, but he also had a very warm human side. We could absolutely trust in him as a supervisor and later as a colleague and friend, in science and beyond. 
Among the many roles Martin Lindauer played during his long academic career, the one he certainly valued most was his role as a dedicated, self-reliant scientist, who was absolutely engaged in research topics which he had developed largely on his own, but which prepared the ground for the growth of future world-wide research activities. Out of this engagement and fascination came what we learned from him first and foremost: the joys of curiosity and the challenge of discovery. 